ARQGA / 917

\title{
TRANSPLANTE ISOGÊNICO DE ILHOTAS DE LANGERHANS NO FÍGADO DE RATOS. (Metodologia para separação e purificação das ilhotas de Langerhans)
}

\author{
Eleazar CHAIB*, Apostolos PAPALOIS**, Ingrid G. M. BRONS*** e Roy Y. CALNE****
}

RESUMO - A maior indicação do transplante de pâncreas ou de ilhotas de Langerhans é o diabetes mellitus do tipo I. O processo deve suprir as necessidades de insulina mantendo os niveis glicêmicos dentro da normalidade. Estudou-se o transplante isogenico de ilhotas de Langerhans no fígado de ratos WAG-RT1 ${ }^{u}$. Com o método de separação e purificação das ilhotas de Langerhans obteve-se 2.834 $\pm 551,64$ ilhotas com pureza de 83 $\pm 2,45 \%$. O transplante de 2.834 $\pm 551,64$ ilhotas de Langerhans no fígado destes animais, normalizou a glicemia que chegou a $35 \mathrm{mmol} / \mathrm{L}$ após indução do diabetes pela estreptozotocina, ficando em 9,62 $\pm 2,65 \mathrm{mmol} / \mathrm{L}$ nos primeiros 10 dias após o enxerto e 7,43 $\pm 0,27 \mathrm{mmol} / \mathrm{L}$ nos dias subseqüentes $(P<0,05)$. O tempo médio de sobrevida das ilhotas transplantadas foi de 73 dias. Assim, o método para separação e purificação de ilhotas de Langerhans de ratos foi eficaz e o isotransplante de ilhotas de Langerhans em ratos foi efetivo na correção do diabetes induzido por estreptozotocina, havendo sobrevida média superior a 73 dias do enxerto e do animal quando os animais foram sacrificados.

DESCRITORES - Transplante das ilhotas de Langerhans. Transplante isogênico. Fígado. Rato.

Trabalho realizado no Departamento de Cirurgia da Universidade de Cambridge, Inglaterra.

* Livre-Docente da Disciplina de Cirurgia do Aparelho Digestivo da Faculdade de Medicina da Universidade de São Paulo - FMUSP (Serviço de Cirurgia do Fígado, Hipertensão Portal e Transplante de Órgãos). Former Honorary Registrar (1991-1993) Departament of Surgery, Addenbrookes Hospital, University of Cambridge School of Medicine, Cambridge, England.

* $\quad$ Biomédico da Universidade de Atenas, Grécia.

*** Pesquisadora-Senior $(\mathrm{PhD})$ da Universidade de Cambridge, Inglaterra.

**** Professor de Cirurgia da Universidade de Cambridge, Inglaterra.

Endereço para correspondência: Dr. E. Chaib - Rua Embaú, 206 - apto.131 - 04039-060 - São Paulo, SP. 


\section{INTRODUÇÃO}

O objetivo do transplante de pâncreas ou de ilhotas de Langerhans é prover fonte de insulina que seja suficiente para manter a glicemia dentro dos limites da normalidade. Como conseqüência, o transplante deve prevenir as complicações secundárias do diabetes, como também melhorar a qualidade de vida dos pacientes, liberando-os da dependência de injeções de insulina.

A maior indicação do transplante de pâncreas ou de ilhotas de Langerhans é o diabetes mellitus do tipo I, doença na qual as células beta das ilhotas de Langerhans são destruídas por processo auto-imune, resultante de inter-relação complexa entre fatores genéticos e ambientais desconhecidos ${ }^{(5)}$.

Antes do início da chamada era "insulínica", o coma diabético era a causa de morte em pelo menos $2 / 3$ dos pacientes com diabetes mellitus do tipo I, de qualquer idade; porém, com a introdução da insulina em 1922, houve notável regressão nestes números, aumentando, significativamente, a longevidade dos doentes $^{(2)}$

Mais de meio século após a introdução do tratamento do diabetes mellitus pela insulina, os diabéticos ainda morrem mais cedo do que os não-diabéticos. A taxa de mortalidade, por sexo e por idade, nos diabéticos é mais alta, em qualquer faixa etária, quando comparada à população normal.

A diferença na taxa de mortalidade é, em parte, dependente da idade. Entre 20 e 40 anos de idade, o risco de morte é 10 ou mais vezes maior no diabético do tipo I do que em não-diabéticos, enquanto em diabéticos acima de 50 anos, é apenas de duas vezes.

A causa de morte está, também, relacionada com a idade: pacientes mais jovens tendem a morrer de nefropatia, enquanto os mais idosos de doenças cardiovasculares ${ }^{(2)}$.
$\mathrm{Na}$ Inglaterra, a causa mais comum de cegueira, no período produtivo da vida, é o diabetes mellitus. A retinopatia diabética é esperada em praticamente todos os diabéticos e pode ser detectada em, aproximadamente, $80 \%$ dos pacientes doentes por mais de 20 anos, e em 100\% daqueles com 40 anos de doença diagnosticada ${ }^{(9)}$.

A prevalência da doença em nosso meio ainda não está bem estabelecida, porém nos Estados Unidos é bem conhecida. Existe mais de 1 milhão de pacientes com diabetes mellitus insulino-dependente naquele país. A incidência anual da doença é de 55 novos casos por milhão de população, ou 12.000 novos casos por ano. A maioria dos casos são crianças, embora em todas as faixas etárias existam grupos de $\operatorname{risco}^{(7,26)}$.

A alternativa de tratamento para estes doentes é o transplante de pâncreas, que se sabe, pode normalizar o metabolismo de carboidratos $^{(23)}$. No entanto, se por um lado esta terapêutica pode prevenir ou reverter as complicações vasculares comumente vistas nos diabéticos tratados com insulina, por outro, parece improvável que o estrito controle da glicemia pela administração de insulina minimize as complicações ${ }^{(14,24)}$.

Os resultados do transplante vascularizado de pâncreas têm melhorado nos últimos anos; no entanto, a cirurgia e a necessidade de imunossupressão continuam sendo responsáveis pela significante morbi-mortalidade do procedimento.

Desde que muitos dos problemas relacionados com este procedimento terapêutico são inerentes à técnica cirúrgica ou da porção exócrina do pâncreas transplantado, a simples implantação de ilhotas purificadas de Langerhans, seria uma alternativa viável.

Muito tem sido feito, nos últimos 20 anos, para o aperfeiçoamento das técnicas de transplante de ilhotas de Langerhans: a grande atração desta modalidade terapêutica é de que as ilhotas podem ser injetadas, por via endovenosa, em órgão bem vascularizado (como por exemplo, o baço ou o fígado), evitandose, assim, a necessidade de intervenção cirúrgica, como também, as inconveniências imunólogicas e inflamatórias conseqüentes do transplante de tecido exócrino pancreático.

Apesar dos resultados encorajadores em roedores, o transplante alogênico de ilhotas de Langerhans em grandes animais, como também no homem, não tem demonstrado produção significativa de insulina, por longos períodos ${ }^{(12}$, ${ }^{20)}$. Por outro lado, o transplante de ilhotas de Langerhans vem enfrentando dificuldades não só na rejeição imunológica, como também problemas anatômicos específicos ${ }^{(16)}$.

Sabe-se que as ilhotas de Langerhans dispersam-se entre os ácinos pancreáticos e constituem entre 1 e $2 \%$ da massa do pâncreas, assim o seu transplante tem necessitado de métodos complexos e às vezes ineficientes de isolamento e purificação das ilhotas.

Com todos estes desafios existe, assim, um campo aberto para a pesquisa e entendimento dos mecanismos fisiopatólogicos relacionados com a aceitação e rejeição do transplante, assim como, da produção de insulina pelas células beta transplantadas.

Neste estudo apresentaremos método eficiente de separação e purificação de ilhotas de Langerhans com vistas ao transplante isogênico em ratos.

\section{MATERIAL E MÉTODO}

O estudo foi realizado em 20 Rattus albinus, sendo 15 (doadores) fêmeas, da raça Wistar (RT1 $\left.{ }^{\mathrm{u}}\right)$ e 5 (receptores) machos, da raça Wistar $\left(\mathrm{RT} 1^{\mathrm{u}}\right)$.

Os animais foram obtidos da OLAC, 1976 Ltd. (Bicester, United Kingdom) e do CBS 
(Central of Biomedical Service - University of Cambridge, UK). Água e dieta foram administrados ad libitum.

Para separação das ilhotas de Langerhans, foram utilizados ratos fêmeas Wistar $\left(\mathrm{RT} 1^{\mathrm{u}}\right)$, de peso corpóreo entre 120 e 210 g. Para receptores das ilhotas de Langerhans, utilizaram-se ratos machos Wistar $\left(\mathrm{RT}^{\mathrm{u}}{ }^{\mathrm{u}}\right)$, com peso corpóreo entre 180 e $320 \mathrm{~g}$, onde o diabetes foi induzido por injeção, na veia peniana, de estreptozotocina.

\section{Separação e purificação das ilhotas de Langerhans}

\section{Digestão do pâncreas}

O pâncreas distendido pela colagenase era colocado em tubo com solução de Hanks e a seguir em banho com água a $37^{\circ} \mathrm{C}$ e incubado por 17 minutos. Tomava-se cuidado para monitorizar o tempo e a temperatura após a água estar a $37^{\circ} \mathrm{C}$.

Afim de se interromper a digestão pancreática, o tubo era retirado da água morna e a solução de Hanks aquecida, era desprezada e substituída pela mesma solução fria, sendo o tecido pancreático colocado em "box" com gelo. A seguir, este passava por peneira com poros de $400 \mathrm{u}$.

O tecido digerido era re-suspenso em $20 \mathrm{~mL}$ de líquido de lavagem (Hanks) e era centrifugado por dois minutos a $1000 \mathrm{rpm}$, sendo este procedimento repetido por duas ou três vezes.

O tempo de centrifugação era curto e a velocidade não muito alta para remover-se apenas células exócrinas e os “debris”.

\section{Método de purificação das Ilhotas de Langerhans}

Após a digestão enzimática tecidual, o pâncreas era lavado como descrito acima e após a decantação do sobrenadante, obtinhase o material para ser purificado.

O método de purificação utilizado foi com Dextran (Sigma Industrial D - 3759) com peso molecular entre 70.000 e 90.000; $169 \mathrm{mg}$ de Dextran eram dissolvidos em $500 \mathrm{~mL}$ de Hanks (densidade $=1094$ ) no período de uma hora, sendo a densidade da nova solução conferida com hidrômetro.

O material digerido era re-suspenso em $10 \mathrm{~mL}$ de Dextran a 31\%, dissolvido em solução de Hanks e misturado cuidadosamente. Os gradientes de Dextran usados foram: $29 \%$ (11,27 mL Dextran + 1,3 mL de Hanks), 25\% (9,8 mL Dextran $+2 \mathrm{~mL}$ de Hanks) e $11 \%$ (4,4 mL Dextran + 6,4 mL Hanks).

Em tubo universal, colocava-se $3 \mathrm{~mL}$ de Dextran a $31 \%$, a seguir a solução obtida (tecido pancreático) era sobreposta por $4 \mathrm{~mL}$ de Dextran a 29\%, $4 \mathrm{~mL}$ a $25 \%$ e $4 \mathrm{~mL}$ a $11 \%$, sendo todo o material centrifugado a $400 \mathrm{rpm}$ por 4 minutos e $2000 \mathrm{rpm}$ por 16 minutos $^{(3)}$.

\section{Separação das ilhotas de Langerhans}

Após a centrifugação, a separação das ilhotas era obtida da interface das seguintes concentrações de Dextran 11\%-25\% e 25\%$29 \%$. A seguir, eram removidas com pipeta plástica de Pasteur e lavadas duas vezes com solução de Hanks: a primeira por três minutos a $1000 \mathrm{rpm}$ e a segunda por um minuto.

Amostra de cada interface era examinada e contada numa placa de Petri, sob visão direta, com auxílio de microscópio. As ilhotas obtidas eram, então, utilizadas imediatamente para o transplante.

\section{Método de contagem das ilhotas isoladas}

O método usado para a contagem do número das ilhotas isoladas era, em resumo, o seguinte: re-suspenção das células em $2 \mathrm{~mL}$ de solução de Hanks misturando-se adequadamente; a seguir, 10 aliquotas de $20 \mathrm{uL}$ eram colocadas em placa de Petri.

As ilhotas eram contadas sob visão direta de microscópio com aumento de 10 vezes.

A fórmula usada para calcular o número de ilhotas era:

média do $\mathrm{n}^{\mathrm{o}}$ total de ilhotas (10 gotas) $\mathrm{x}$ $100=\mathrm{n}^{\circ}$ total de ilhotas em $2 \mathrm{~mL}$

\section{Identificação das ilhotas de Langerhans}

Embora as ilhotas, em roedores, possam ser facilmente identificadas usando-se microscópio de dissecção, método simples de coloração das mesmas foi usado para quantificar-se a pureza da preparação.

As ilhotas podem ser coradas antes ou depois da separação com DTZ (diphenylthiocarbazone - Sigma D-5130), que facilita a visualização das células na interface das concentrações do Dextran.

Também foi demonstrado que este método de coloração não altera a função das ilhotas in vitro e in vivo ${ }^{(11)}$. O DTZ é substância que se liga às moléculas de zinco nos grânulos de insulina, dando a cor avermelhada.

A solução de coloração foi preparada acrescentando-se seis gotas de $1 \mathrm{mmol}$ de hidróxido de amônio (30\%) a 20 mg de DTZ dissolvido em $6 \mathrm{~mL}$ de etanol a $96 \%$, o que resultou numa solução de $13 \mathrm{mmol}$ de DTZ com $\mathrm{pH}=7,8$.

A solução final com $\mathrm{pH}=7,4$ foi obtida acrescentando-se $300 \mathrm{uL}$ desta solução a 100 $\mathrm{mL}$ de PBS (phosphate-buffered saline). Assim, um volume do pâncreas digerido e nove volumes da solução de DTZ foram misturados e incubados à temperatura ambiente por 10 a 15 minutos. 


\section{Procedimento operatório}

Todo procedimento operatório foi realizado sob condições limpas. Os instrumentos cirúrgicos eram colocados em recipiente com etanol a $70 \%$, pelo menos seis horas antes do ato cirúrgico.

Os ratos eram anestesiados em câmara de vidro utilizando-se éter etílico (May; Baker Ltd., Dagenham, England). Esta anestesia era utilizada para os procedimentos de curta duração. Para as intervenções prolongadas usava-se o Hypnorm $(0,04 \mathrm{~mL} / 100 \mathrm{~g}$ de peso corpóreo) (Janssen Pharmaceuticals Ltd., Grove Oxford - OX12 ODQ, UK), citrato de fentanyl $(0,315 \mathrm{mg} / \mathrm{mL})$ e fluanizone $(10 \mathrm{mg}$ / $\mathrm{mL}$ ) através de injeção intramuscular na coxa dos animais, juntamente com o Diazepan (CP Pharmaceuticals Ltd, Wrexham, UK), $10 \mathrm{mg} /$ $2 \mathrm{~mL}$, por via intraperitonial.

A tricotomia do abdome era realizada com máquina elétrica e o animal era colocado em prancha de cortiça na posição supina, com os membros fixados.

\section{Indução do diabetes mellitus}

O animal era submetido a anestesia superficial por inalação de éter etílico (May; Baker Ltd., Dagenham, England) e colocado em posição supina em prancha de cortiça. Neste momento, colhia-se da veia da cauda do animal, amostra sangüínea para dosagem da glicemia sérica. A seguir, a veia peniana era canulada (com seringa de insulina de $1 \mathrm{~mm}$ e agulha de $12 \mathrm{~mm}$ x 0,4 $\mathrm{mm}$ ) e a estreptozotocina (60 $\mathrm{mg} / \mathrm{kg}$ ) era injetada (a estreptozotocina era dissolvida em PBS na concentração de $10 \mathrm{mg} /$ $\mathrm{mL}$ ). $\mathrm{O} \mathrm{pH}$ do PBS era ajustado previamente para 4,5 com ácido cítrico).

A seguir, suspendia-se a anestesia inalatória e o animal era colocado em gaiola isolada para controle da glicemia sérica a cada dois dias.
Os animais com níveis de glicemia sérica acima de $13 \mathrm{mmol} / \mathrm{L}$ foram utilizados para o transplante de ilhotas de Langerhans.

\section{Cirurgia do doador - pancreatectomia}

Utilizaram-se 15 ratos, fêmeas, da raça Wistar $\left(\mathrm{RT}^{\mathrm{u}}{ }^{\mathrm{u}}\right)$, com peso corpóreo que variou de 120 a 210 gramas.

Incisão mediana era feita no abdome do animal e o ducto biliopancreático era visualizado. A ligadura da parte proximal do ducto era feita o mais próximo possível do duodeno, usando-se fio monofilamentar 5-0 (Ethicon Ltd., UK) e reparando-o com uma pinça hemostática tipo "mosquito" para visualização de sua parte distal.

O ducto era, então, canulado com auxílio de microscópico (Zeiss, Germany - OPM1 6-SH), inserindo-se cânula de plástico fina e amarrando-a com fio de algodão 4-0.

Antes da injeção enzimática, o animal era exsanguinado, por secção da aorta abdominal, na emergência dos vasos ilíacos.

Após o coração parar de bater, volume de 4 a $5,5 \mathrm{~mL}(25 \mathrm{~mL} / \mathrm{kg})$ de solução de colagenase (Sigma do tipo XI, C-7657, na dosagem de $0,7 \mathrm{mg} / \mathrm{mL}+$ DNase dissolvida em HBSS (Hanks balanced salt solution) Sigma D-0876) era injetado no ducto biliopancreático, onde se observava a distensão pancreática.

Após o órgão encontrar-se totalmente preenchido pela colagenase, era realizada a pancreatectomia, dissecando-se o pâncreas da grande curvatura gástrica, do duodeno, do retroperitônio, do intestino grosso, do intestino delgado e do baço, com tesoura de microcirurgia, tomando-se o cuidado de não romper-se a cápsula pancreática, para que não houvesse extravazamento da colagenase.
A seguir, o pâncreas era colocado em tubo universal que, imediatamente, era transferido para "box" de gelo, e levado ao laboratório. $\mathrm{O}$ tempo de isquemia fria não era superior a 30 minutos.

\section{Cirurgia do receptor - transplante de ilhotas de Langerhans}

Ratos, fêmeas, da raça Wistar (RT1 ${ }^{\mathrm{u}}$ ), pesando entre 180 e $320 \mathrm{~g}$ foram usados como receptores de ilhotas de Langerhans de doadores fêmeas da raça Wistar (RT1 $\left.{ }^{\mathrm{u}}\right)$.

O diabetes era induzido por injeção endovenosa de estreptozotocina $(60 \mathrm{mg} / \mathrm{kg})$ na veia peniana. Quatro dias depois da indução do diabetes, o animal era anestesiado com a associação Hypnorm intramuscular (0,04 mL/100 g de peso corpóreo) e Diazepan intraperitonial $(0,05 \mathrm{~mL} / 100 \mathrm{~g}$ de peso corpóreo), colhendo-se amostra sangüínea da veia da cauda do rato, para dosagem da glicemia antes da laparotomia.

O estômago, o intestino grosso e o delgado eram envolvidos em gaze úmida e afastados para o lado direito do abdome. A veia porta era visualizada e puncionada com Butterfly $\mathrm{n}^{\mathrm{o}} 23$ (Venisystems, TM, Abbott, Ireland Ltd.), com agulha de 19,1 mm e diâmetro de $0,5 \mathrm{~mm}$.

As ilhotas suspensas em $0,5 \mathrm{~mL}$ de PBS eram aspiradas em seringa de $1 \mathrm{~mL}$ com solução salina e injetadas, via veia porta, no fígado. Após a injeção, a agulha era retirada da veia porta e esponja de material absorvível (Spongostan e Standard 70 × $50 \times 10 \mathrm{~mm}$, Ferrosan - Denmark) era colocada no local da punção, comprimindo-se o vaso suavemente por dois minutos, para evitar o sangramento.

O abdome era, então, fechado em dois planos de sutura contínua usando-se algofil 4-0 para o plano muscular e para a pele. 
O animal era seguido diariamente no pósoperatório e dosagens de glicemias séricas eram feitas a cada dois dias.

$\mathrm{Na}$ análise estatística utilizou-se o teste de Mann-Whitney na comparação das glicemias antes e depois do transplante com nível de significância de 5\%.

\section{RESULTADOS}

\section{Cirurgia do doador}

Com método de separação e purificação das ilhotas de Langerhans, obteve-se $2.834 \pm$ 551,64 ilhotas com pureza de $83 \pm 2,45 \%$ (Tabela 1).

\section{Cirurgia do receptor}

A dose de estreptozotocina utilizada para a indução do diabetes mellitus, nos animais deste grupo, foi de $15,14 \pm 2,91 \mathrm{mg}$, obtendose níveis de glicemia sérica de 33,82 $\pm 2,66$ $\mathrm{mmol} / \mathrm{L}$ (Tabela 1 ).

O transplante de $2.834 \pm 551,64$ ilhotas de Langerhans no fígado destes animais, normalizou a glicemia que chegou a 9,62 \pm 2,65 mmol/L, nos primeiros 10 dias após o enxerto e 7,43 $\pm 0,27 \mathrm{mmol} / \mathrm{L}$ nos dias subseqüentes, ambas as diferenças significativas (Tabela 1). A demonstração gráfica destes valores está na Figura 1.

O tempo médio de sobrevida das ilhotas transplantadas está na Tabela 2.

\section{DISCUSSÃO}

O método de separação e purificação das ilhotas de Langerhans, utilizado neste estudo

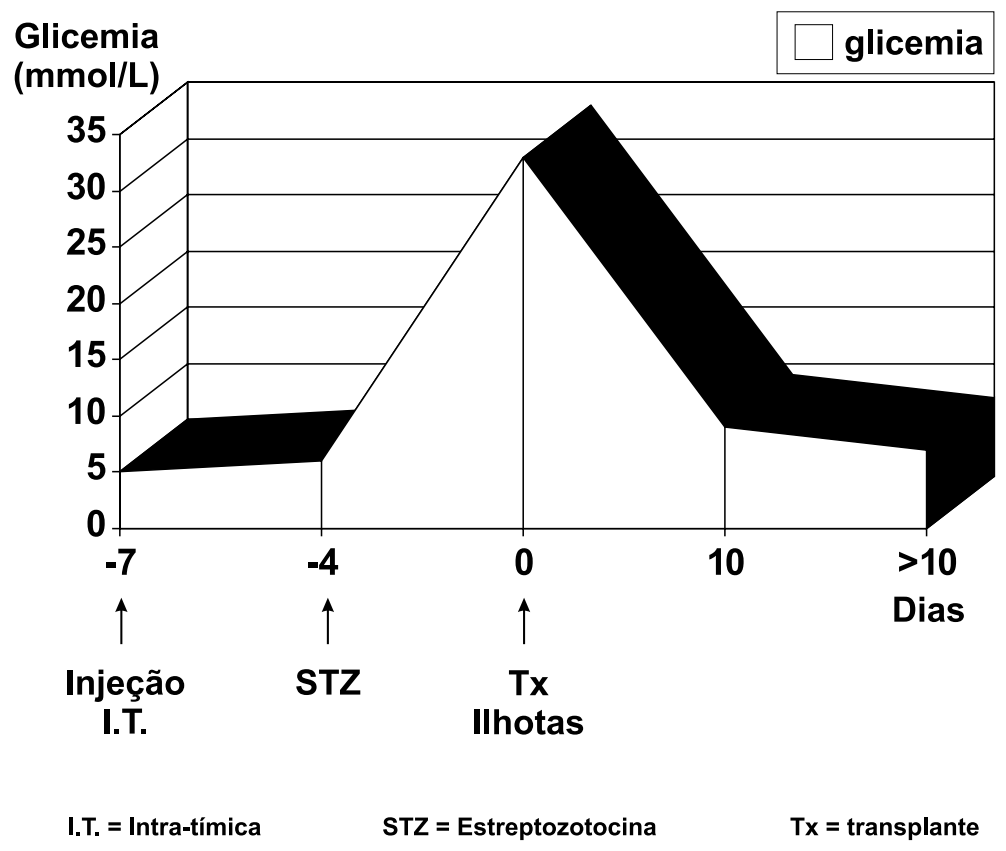

Figura 1 - Transplante isogênico de ilhotas de Langerhans (WAG-RT1 ${ }^{\text {u }}$ - WAG-RT1 ${ }^{\text {u}}$ ) é complexo e por necessitar de várias etapas subseqüentes, serão discutidos aspectos técnicos e históricos com relação ao uso de ilhotas isoladas e a injeção das mesmas na veia porta.

A técnica de ilhotas isoladas é das mais promissoras, pelo menos teoricamente, e das que tem, com maior freqüência, levado o transplante de ilhotas ao sucesso ${ }^{(10)}$.

Da preparação do pâncreas disperso, as ilhotas são separadas dos ácinos pancreáticos,

Tabela 1 - Transplante isogênico de ilhotas de Langerhans (WAG-RT1 ${ }^{\mathrm{u}}$ - WAG-RT1 ${ }^{\mathrm{u}}$ )

\begin{tabular}{cccccccccc}
$\begin{array}{c}\text { STZ } \\
(\mathbf{m g})\end{array}$ & $\begin{array}{c}\text { Glic. } \\
\text { dia } \mathbf{- 4}\end{array}$ & $\begin{array}{c}\text { Peso } \\
\mathbf{( g )}\end{array}$ & $\begin{array}{c}\text { Glic. } \\
\text { dia } \mathbf{0}\end{array}$ & $\begin{array}{c}\text { Glic. } \\
\mathbf{1 - 1 0}\end{array}$ & $\begin{array}{c}\text { Glic. } \\
>\mathbf{1 0}\end{array}$ & $\begin{array}{c}\text { Ilhotas } \\
\mathbf{n}^{\mathbf{1 0}}\end{array}$ & $\begin{array}{c}\text { Pureza } \\
\mathbf{\%}\end{array}$ & $\begin{array}{c}\text { Peso } \\
(\mathbf{g}) \\
\text { depois }\end{array}$ \\
\hline 15,6 & 7,98 & 240 & 32,9 & 7,96 & 7,643 & 2380 & 80 & 310 \\
16,9 & 6,47 & 260 & 39,1 & 10,633 & 7,64 & 3450 & 85 & 350 \\
10,8 & 7,03 & 180 & 31,9 & 6,8 & 7,24 & 3440 & 85 & 230 \\
19,2 & 6,22 & 320 & 32,8 & 14,3 & 7 & 2080 & 85 & 370 \\
13,2 & 7,39 & 220 & 32,4 & 8,4 & 7,65 & 2820 & 80 & 300 \\
15,14 & 5,61 & 244 & $33,82 *$ & $9,62 *$ & $7,43 *$ & 2834 & 83 & 312 \\
2,91 & 2,63 & 46,3 & 2,66 & 2,65 & 0,27 & 551,64 & 2,45 & 48,33
\end{tabular}

* diferente significativamente para $P<0,05$ 
Tabela 2 - Sobrevida do isotransplante de ilhotas de Langerhans no fígado de ratos

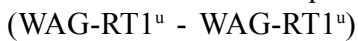

\begin{tabular}{lcc}
\hline $\mathrm{N}^{\mathrm{o}}$ de ratos & $\begin{array}{c}\text { Sobrevida das ilhotas } \\
\text { e dos animais } \\
(\text { dias })\end{array}$ & $\begin{array}{c}\text { Tempo médio de } \\
\text { sobrevida das ilhotas }\end{array}$ \\
\hline 5 & $93,86,73,68,60$ & 73 \\
\hline
\end{tabular}

ductos e componentes vasculares, de duas maneiras: com pipeta ou por centrifugação do preparado, através de concentrações diferentes de Ficoll.

Embora este método resulte em grande perda de ilhotas (mais de 95\%) ele é capaz de coletar entre 150 e 450 ilhotas por pâncreas de rato. Sabe-se que, para o transplante de ilhotas ser bem sucedido, necessita-se de, pelo menos, 600 a 1500 ilhotas, assim de dois a seis doadores, geralmente, serão utilizados.

Agentes que diminuem o conteúdo enzimático das células acinares (pilocarpina), que causam atrofia acinar (DL-etionina), ou destruição acinar (anticorpo anti-célula acinar) podem ser úteis para diminuir o conteúdo acinar nas preparações das ilhotas ${ }^{(13,17,21,22,25)}$.

Outras preparações usam filtro no qual o tecido pancreático é colocado para digestão ${ }^{(21)}$. As ilhotas que são separadas do tecido pancreático logo no início do processo são filtradas, protegendo-as, assim, do excesso de digestão, enquanto o resto do tecido pancreático é preparado para liberação de novas ilhotas ${ }^{(22)}$.

A modificação e a melhora destes métodos têm, mais recentemente, mostrado melhora na separação das ilhotas, de modo que o transplante tem sido bem sucedido, às vezes, com ilhotas provindas de um único doador. No entanto, múltiplos doadores são, ainda, necessários para o sucesso do transplante, conforme demonstraram diversos autores ${ }^{(4,6)}$.

A inoculação de ilhotas na veia porta foi descrita pela primeira vez por KEMP et al. ${ }^{(8)}$, que imaginaram que a insulina produzida pelas ilhotas seria efetivamente aproveitada, pois atingiria o fígado diretamente.

A comprovação desta teoria é que apenas 300 a 600 ilhotas isoladas de ratos (preparadas de três a seis doadores), inoculadas por via portal, cura a diabetes, enquanto são necessárias de 800 a 2400 ilhotas (de 4 a 12 doadores) quando se usa a via peritonial $^{(19)}$.

As ilhotas que se localizam em ramos portais terminais, mesmo antes de sua neovascularização, produzem insulina em 24 horas e revertem o diabetes. A neovascularização das ilhotas, por sua vez, ocorre em poucos dias e a implantação definitiva é estimada em $50 \%{ }^{(18)}$.

A grande vantagem do fígado como local de transplante das ilhotas é sua dupla irrigação sangüínea, o que permite a total oclusão das vênulas portais, causada pela embolização e não infartando o local do transplante, que permanece nutrido pelo sangue arterial.

O transplante intra-arterial de ilhotas em áreas não providas de dupla irrigação (ex. o baço) resulta em seu infarto, com possível insucesso do enxerto.

Se o pâncreas não purificado disperso é inoculado via portal, as enzimas ativadas do tecido transplantado podem ocluir os ramos portais principais causando: hipertensão portal, lesão hepática, hipotensão e coagulação vascular disseminada ${ }^{(15)}$. Estas alterações são severas em cães, embora tenha sido, também, descrita em ratos e humanos.

Outro risco potencial da via portal é a disseminação de microorganismos contaminados. Também a via portal não é acessível facilmente, a inoculação das ilhotas tem sido feita geralmente no intra-operatório, embora a via transcutânea transhepática também tenha sido usada em auto-transplante em humanos ${ }^{(1)}$.

Apesar das desvantagens da via portal, esta tem se mostrado mais efetiva que as outras vias e deve ser considerada a de escolha na maior parte dos transplantes, especialmente se forem usadas preparações purificadas não tóxicas de ilhotas.

Para aplicarmos os conceitos expostos nos parágrafos anteriores, idealizamos o grupo isôgenico de transplante das ilhotas, no qual se utilizaram, tão somente, animais com complexos de histocompatibilidade maior semelhantes. Dessa forma, portanto, não houve necessidade de qualquer tipo de imunossupressão. Este grupo serviu, em última análise, para o controle do método de separação e purificação das ilhotas de Langerhans.

Assim, neste grupo a injeção de 15,14 \pm 2,91 mg de estreptozotocina, na veia peniana, mostrou-se efetiva na produção do diabetes mellitus, visto que os animais possuiam no quarto dia pré-transplante das ilhotas, glicemia de $5,61 \pm 2,63 \mathrm{mmol} / \mathrm{L}$, e no dia 0 (dia do transplante das ilhotas ), glicemia de 33,82 \pm 2,66 mmol/L, elevação significativa estatisticamente.

Após o transplante de $2834 \pm 551,64$ ilhotas no fígado por via portal, a glicemia nos primeiros dias pós-transplante $\left(1^{\circ}\right.$ ao $\left.10^{\circ}\right)$ mostrou queda significativa, ficando em torno de $9,62 \pm 2,65 \mathrm{mmol} / \mathrm{L}$. 
Esta queda e normalização da glicemia no pós-transplante evidenciou que as ilhotas de Langerhans foram preparadas adequadamente bem como foram efetivas na produção de insulina, podendo-se supor que houve boa implantação das células transplantadas no parênquima hepático.

Se observarmos os níveis glicêmicos nos dias subseqüentes ao transplante das ilhotas de Langerhans $\left(>10^{\circ}\right)$, veremos que a queda da glicemia também foi significativa com relação ao dia do transplante (dia 0), ficando evidente, agora, o sucesso do transplante destas células como demonstra a Figura 1.

Este fato foi constatado ao longo do experimento, pois os animais ganharam peso corpóreo total $(244 \pm 46,3 \mathrm{~g}$ no prétransplante para $312 \pm 48,33$ g no póstransplante), bem como se mantiveram com glicemia normal por, em média, 73 dias (Tabela 2), quando foram, então, sacrificados.

Assim, nas condições experimentais do presente estudo, o método para separação e purificação de ilhotas de Langerhans de ratos foi eficaz e o isotransplante de ilhotas de Langerhans, em ratos, foi efetivo na correção do diabetes induzido por estreptozotocina, havendo sobrevida média superior a 73 dias do enxerto e do animal.

Chaib E, Papalois A, Brons IGM, Calne RY. Isogenic islet transplantation on the rat liver. Method for isolation and purification of the rat islets.

Arq Gastroenterol, 2000; 37(1):44-51.

ABSTRACT - The major indication for pancreas or islet transplantation is diabetes mellitus type I. This process has to supply the insulin

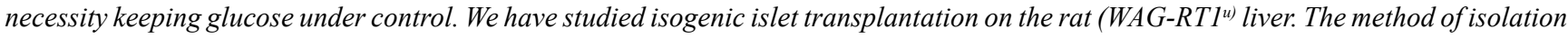
and purification of the islets obtained $2.834 \pm 551,64$ islets with purity of $83 \pm 2,45 \%$. Diabetes was induced by streptozotocin and seric glucose prior transplantation was $35 \mathrm{mmol} / \mathrm{L}$. The islet transplantation of 2.834 $\pm 551,64$ islets in the rat liver has normalized glucose test from 9,62 2,65 mmol/L 10 days after transplantation to 7,43 $\pm 0,27 \mathrm{mmol} / \mathrm{L}$ later in the follow-up $(P<0,05)$. The median survival time of the islets was 73 days. In conclusion both the method of isolation and purification of the islets and islet transplantation was effective in the control of the diabetes induced by streptozotocin with median survival time of both islet and rat more than 73 days when rats were sacrificied.

HEADINGS - Islets of Langerhans transplantation. Transplantation isogeneic. Liver. Rats.

\section{REFERÊNCIAS BIBLIOGRÁFICAS}

1. Barker CF, Naji A. Pancreatic and islet cell transplantation. In: Howard JM, Jordan GL, Reber HA, editors. Surgical diseases of the pancreas. Philadelphia: Lea; Febiger; 1987. p.912.

2. Brent L, Sells RA. Organ transplantation: current clinical and immunological concepts. London: Baillière Tindall; 1989.

3. Chaib E, Brons IGM, Papalois A, Calne RY. Does intrathymic injection of donor antigen-presenting cells before allogeneic rat islet transplantation prolong graft survival? Transpl Intern $1994 ; 7: 423$.

4. Dibelius A, Konigsberger H, Walter P, Permanetter W, Brendel W, Specht BU. Prolonged reversal of diabetes in the rat by transplantation of allogeneic islets from a single donor and cyclosporine treatment. Transplantation 1986;41:426.

5. Eisenbarth GS. Type I diabetes mellitus: a chronic autoimmune disease. N Engl J Med 1986;314:1360.

6. Gotoh M, Maki T, Kiyoizumi T, Satomi S, Monaco AP. An improved method for isolation of mouse pancreatic islets. Transplantation 1985;40:437.

7. Harris MJ, Hanaman RF. Diabetes in America. Bethesda, Maryland: NIH Publication; 1985.

8. Kemp CB, Knight MJ, Scharp DW, Ballinger WF, Lacy PE. Effect of transplantation site on the results of pancreatic islet isografts in diabetic rats. Diabetologia 1973;9:486. 
9. Krolewski AS, Warram JR, Rand LI. Risk of proliferative diabetic retinopathy in type I diabetes, a 40 year follow-up study. Diabetes Care 1986;9:443.

10. Lacy PE, Kostianvsky M. Method for the isolation of intact islets of Langerhans from the rat pancreas. Diabetes $1967 ; 16: 35$.

11. Latif ZA, Noel K, Alejandro R. A simple method of staining fresh and cultured islets. Transplantation 1988;45:827.

12. London NJ. Clinical studies of human islet transplantation. Ann R Coll Surg Engl 1995;77:263.

13. Long JA, Adair WF, Scharp DW. An immunological approach to islet cell purification. J Cell Biol 1982;95:4061.

14. Mauer SM, Sutherland DER, Steffes MW. Pancreatic islet transplantation: effects on the glomerular lesions of experimental diabetes in the rat. Diabetes 1974;23:748.

15. Mehigan DG, Ball WR, Zuidema GD. Disseminated intravascular coagulation and portal hypertension following pancreatic islet autotransplantation. Ann Surg 1980;191:287.

16. Miranda MP. Estado atual e experiência clínica inicial com transplante de pâncreas. São Paulo, 1997. [Dissertação de Mestrado - Faculdade de Medicina da Universidade de São Paulo].

17. Payne WD, Sutherland DER, Matas AJ. DL-ethionine treatment of adult pancreatic donors: amelioration of diabetes in multiple recipients with tissue from a single donor. Ann Surg 1979;189:248.

18. Pipeleers-Marichal M, Pipeleers DG, Cutler J. Metabolic and morphologic studies in intraportal transplanted rats. Diabetes 1976;25:1041.
19. Reckard CR, Ziegler MM, Barker CF. Physiological and immunological consequences of transplanting isolated pancreatic islets. Surgery 1973;74:91.

20. Ricordi C, Tsakis AG, Carrol PB, Zeng Y, Rilo HLR, Alejandro R, Shapiro R, Fung JJ, Demetris AJ, Mintz, DH, Starzl TE. Human islet isolation and allotransplantation in 22 consecutive cases. Transplantation 1992;53:407.

21. Scharp DW, Murphy JJ, Newton WT, Ballinger WF, Lacy PE. Transplantation of islets of Langerhans of diabetic rhesus monkeys. Surgery $1975 ; 77: 100$.

22. Scharp DW. Isolation and transplantation of islet tissue. World $\mathrm{J}$ Surg 1984;8:143.

23. Sutherland DER, Najarian JS, Greenberg BZ, Senske BJ, Anderson GE, Francis RS, Goetz FC. Hormonal and metabolic efffects of an endocrine graft: vascularized segmental transplantation of the pancreas in insulin-dependent patients. Ann Intern Med $1981 ; 95: 537$.

24. Tchobroutrky G. Relation of diabetic control to development of microvascular complications. Diabetes 1978;15:143.

25. Vrobova H, Theodorosa NA, Tyhurst M, Howell SL. Transplantation of islets of Langerhans from pilocarpine-treated rats: a method of enhancing islet yield. Transplantation $1979 ; 28: 433$.

26. West KM. Epidemiology of diabetes and it's vascular lesions. New York: Elsevier; 1978.
Recebido para publicação em 11/3/1999. Aprovado para publicação em 16/7/1999. 